\title{
SISTEM INFORMASI ASET ORGANISASI MUHAMMADIYAH CABANG MINGGIR YOGYAKARTA BERBASIS WEBSITE
}

\author{
Agung Nugroho ${ }^{1)}$, Isna Arifatul Hilda ${ }^{2)}$ \\ 1) Sistem Informasi Universitas AMIKOM Yogyakarta \\ 2) Sistem Informasi Universitas AMIKOM Yogyakarta \\ email : agungnugroho@amikom.ac.id ${ }^{1)}$,isnahilda@students.amikom.ac.id ${ }^{2)}$
}

\begin{abstract}
Abstraksi
Kebutuhan Informasi aset Organisasi Muhammadiyah Cabang Minggir saat ini dilakukan dengan meminta kepada pengelola amal usaha untuk aset data. Akibatnya Pimpinan Cabang tidak bisa mendapatkan informasi aset secara langsung saat dibutuhkan. Untuk mengatasi masalah tersebut, peneliti mencoba menganalisis dan membangun sistem informasi organisasi aset menggunakan metode pengembangan sistem informasi SDLC (Systems Development Life Cycle) dengan model Waterfall, desain model proses DFD (Data Flow Diagram), desain model data ERD (Entity Relationship Diagram), desain antarmuka, dan desain database. Aplikasi yang dihasilkan berupa prototype sistem informasi aset yang akan digunakan Pimpinan Cabang untuk inventarisasi aset. Aplikasi berbasis website responsif yang fleksibel untuk diakses dari segi waktu dan tempat serta mampu menghadirkan antarmuka yang dapat beradaptasi dengan perangkat pengguna.
\end{abstract}

\section{Kata Kunci :}

Sistem, informasi, waterfall, website, inventaris aset

\begin{abstract}
Fulfilling the information asset needs of the Muhammadiyah Organization Branch Minggir at this time must be done by asking to manager amal usaha for data asset. It result in Pimpinan Cabang can't get asset information directly when needed. To solve this problem, researcher try to analyze and built an information system of asset organization using information system development method SDLC (Systems Development Life Cycle) with model Waterfall, process model design DFD (Data Flow Diagram), data model design ERD (Entity Relationship Diagram), interface design, and database design. The resulting application is a prototype of asset information system which will be used by Pimpinan Cabang for asset inventory. The application is responsive website based that flexible to be accessed in terms of time and place and capable of presenting an interface that can adapt to the user's device.
\end{abstract}

\section{Keywords :}

Information system, waterfall, responsive website, asset inventory

\section{Pendahuluan}

Data aset organisasi Muhammadiyah Cabang Minggir saat ini ada yang sudah tercatat dan ada pula yang belum. Untuk data yang sudah tercatat masih tersebar pada tiap-tiap amal usaha yang menggunakan sehingga ketika Pimpinan Cabang membutuhkan datanya harus meminta kepada pengelola amal usaha terlebih dahulu. Selain itu, masih ada pula data aset organisasi yang belum tercatat baik dalam bentuk tulisan tangan maupun digital. Adanya inovasi sebuah sistem informasi diharapkan mampu menjadi wadah bagi data aset organisasi baik yang sudah tercatat namun masih tersebar maupun yang sedang akan dicatat.

Berdasarkan permasalahan yang ada dapat disimpulkan suatu rumusan masalah yaitu, "Bagaimana cara membuat website sistem informasi aset pada organisasi Muhammadiyah Cabang Minggir?"
Adapun penelitian ini memiliki maksud dan tujuan yaitu :

1) Menghasilkan sebuah prototype sistem informasi aset sebagai wadah untuk data aset organisasi

2) Memberikan kemudahan arus informasi aset bagi organisasi

3) Memberikan pembaruan data secara real time

\section{Metode Penelitian}

Metode penelitian yang digunakan dalam pembuatan sistem informasi aset adalah sebagai berikut:

1. Metode Pengumpulan Data Metode yang digunakan untuk mengumpulkan data sebagai berikut:

1) Metode Observasi

2) Metode Wawancara 


\section{3) Metode Studi Pustaka}

2. Metode Analisis

Metode analisis yang digunakan adalah PIECES.

3. Metode Perancangan

Metode perancangan yang diusulkan adalah menggunakan model flowchart untuk menggambarkan alur kerja sistem, model DFD (Data Flow Diagram) untuk menggambarkan aliran data dalam sistem, model ERD (Entity Relationship Diagram) untuk menggambarkan perancangan database sistem.

\section{Tinjauan Pustaka}

Penelitian lain yang telah dilakukan sebelumnya serta dijadikan sebagai bahan acuan yang berhubungan dengan penelitian ini yaitu:

Novi Oktaviani, I Made Widiarta dan Nurlaily dari Program Studi Informatika, Fakultas Teknik, Universitas Teknologi Sumbawa menuliskan penelitian yang berjudul "Sistem Informasi Inventaris Barang Berbasis Web pada SMP Negeri 1 Buer" menjelaskan bahwa sistem informasi telah selesai dibuat berdasarkan perancangan sistem yang dilakukan sebelumnya menggunakan DFD. Sistem dibangun menggunakan PHP dan sublime text serta untuk pengumpulan datanya menggunakan metode wawancara dan observasi. Penelitian ini dengan penelitian yang penulis lakukan memiliki persamaan dalam metode perancangan sistem yang digunakan yaitu DFD dan ERD serta memiliki perbedaan pada objek studi kasus penelitian. [1]

Volvo Sihombing dan Gomal Juni Yanris dari Fakultas Sains dan Teknologi, Manajemen Informatika, Universitas Labuhanbatu pada penelitiannya yang berjudul "Penerapan Aplikasi dalam Mengolah Aset Desa (Studi Kasus : Kepenghuluan Sri Kayangan)" menjelaskan bahwa dengan adanya aplikasi membuat data aset desa dapat terjangkau secara keseluruhan dan terarsip dalam komputer, mampu membantu pihak-pihak terkait dalam pembuatan laporan serta menjamin arsip data aset dalam jangka waktu yang panjang. Penelitian ini dengan penelitian yang penulis lakukan memiliki persamaan berbasis aplikasi web serta memiliki perbedaan pada objek studi kasus penelitian. [2]

Selain itu, Sanjaya Pinem dan Victor Maruli Pakpahan dari Program Studi Teknik Informatika, Universitas Efarina melakukan penelitian dengan judul "Aplikasi Inventarisasi Aset Berbasis Web Dengan Metode Waterfall" menghasilkan sebuah sistem informasi yang didasarkan pada observasi dan wawancara yang telah dilakukan. Perancangan sistem menggunakan Use Case Diagram dan Activity Diagram. Sistem berbasis website memudahkan pengguna untuk mengaksesnya serta dengan adanya sistem, pengolahan dan pencatatan data inventarisasi dapat mudah digunakan pengguna. Penelitian ini dengan penelitian yang penulis lakukan memiliki persamaan dalam metode pengembangan sistem yang digunakan yaitu waterfall serta perbedaan metode perancangan sistem yang pada penelitian ini menggunakan UML sedangkan penulis menggunakan ERD, DFD, dan flowchart. [3]

\section{Landasan Teori}

\section{Sistem}

Mc. Leod (1995) mengartikan sistem sebagai elemen yang saling terintegrasi dan memiliki kesamaan maksud untuk mencapai tujuan tertentu. [4]

\section{Informasi}

Informasi adalah data yang telah melalui proses pengolahan dan menjadi suatu bentuk yang memiliki arti bagi penggunanya serta memiliki manfaat untuk pengambilan keputusan saat ini atau masa yang akan datang. (Davis, 1995) [4]

\section{Sistem Informasi}

Sistem informasi dalam organisasi dapat diartikan sebagai sistem yang mampu memberikan informasi bagi seluruh tingkatan pelaku organisasi agar dapat menyediakan informasi kapan saja ketika diperlukan. Sistem ini mampu mengambil, mengolah hingga menyimpannya dan mengkomunikasikan informasi yang diterima menggunakan sistem informasi atau peralatan sistem yang lain. [5]

\section{Inventarisasi Aset}

Inventarisasi aset adalah kegiatan mendata, mencatat, melaporkan hasil pendataan, serta mendokumentasikan aset baik yang berwujud maupun tidak berwujud dalam suatu waktu tertentu. Kegiatan ini bertujuan untuk mendapatkan seluruh data aset yang dimiliki suatu organisasi atau instansi (Gima, 2013) [3]

\section{Website}

Website merupakan salah satu aplikasi yang didalamnya berisi dokumen multimedia berupa teks, gambar, suara, animasi dan video dengan menggunakan protokol Hypertext Transfer Protocol (HTTP) dan browser untuk mengaksesnya.[10] Browser adalah aplikasi yang mampu menjalankan dokumen-dokumen yang ada dalam website dengan cara diterjemahkan. [6]

\section{Metode Penelitian}

Alur penelitian yang digunakan ditunjukkan pada gambar 1 dibawah ini: 


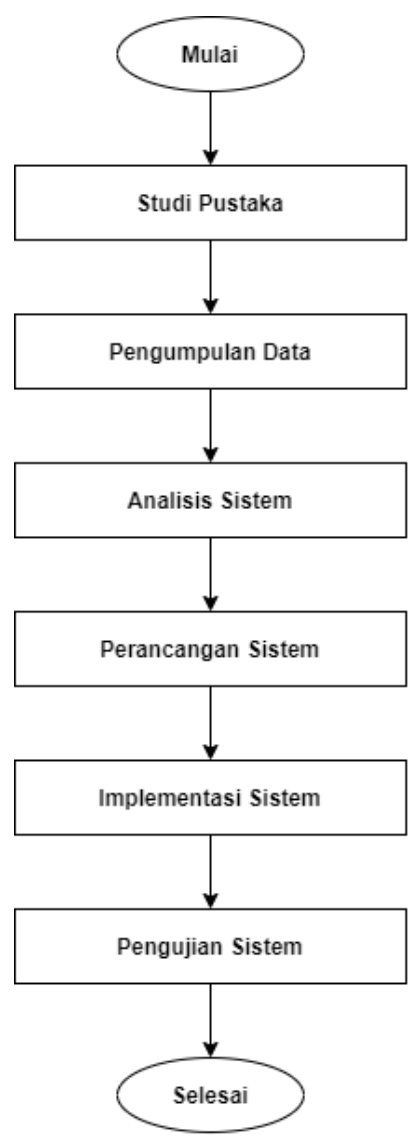

Gambar 1. Alur Penelitian

Berdasarkan pada gambar di atas, alur penelitian yang digunakan adalah sebagai berikut:

1) Studi Pustaka

Dilakukan dengan cara membaca berbagai sumber referensi agar dapat dijadikan acuan guna menyelesaikan permasalahan objek

2) Pengumpulan Data

Dilakukan dengan cara tanya jawab kepada Pimpinan Cabang guna mendapatkan informasi tentang permasalahan objek

3) Analisis Sistem

Pada tahap ini penulis akan menganalisis halhal seperti permasalahan objek, solusi yang diusulkan, analisis kebutuhan dan kelayakan akan sistem yang diusulkan

4) Perancangan Sistem

Penulis merancang berbagai model yang akan diterapkan untuk sistem yang diusulkan meliputi perancangan model proses, perancangan model data, serta perancangan interface/antarmuka

5) Implementasi Sistem

Pada perancangan yang telah penulis lakukan sebelumnya akan diterapkan pada tahap ini melalui proses coding atau penulisan kode program bahasa pemrograman

6) Pengujian Sistem

Sistem yang telah berhasil dibuat akan melalui proses pengujian untuk memastikan kualitas sistem telah terjamin dan tidak ada kesalahan.[7]

\section{Hasil dan Pembahasan}

\section{Analisis Kelemahan Sistem}

Analisis kelemahan digunakan untuk mengetahui permasalahan pada sistem lama. Metode yang digunakan adalah PIECES.[8] Analisis ini memperhatikan aspek kinerja, informasi, ekonomi, keamanan, efisiensi dan layanan.[9] Hasil analisis yang telah dilakukan menunjukkan bahwa sistem lama memiliki kelemahan pada aspek kinerja, keamanan, efisiensi dan layanan.

\section{Analisis Kebutuhan Fungsional}

Kebutuhan fungsional pada sistem yang diusulkan terdiri dari 2 pengguna yaitu Pimpinan Cabang dan Pengelola Amal Usaha.

\section{Analisis Kebutuhan Non Fungsional}

Kebutuhan non fungsional pada sistem yang diusulkan adalah sebagai berikut:
1) Perangkat Keras
2) Perangkat Lunak
3) Keamanan
4) Informasi

\section{Analisis Kelayakan Teknologi}

Sistem yang diusulkan telah memenuhi kelayakan teknologi yang didasarkan pada adanya teknologi website sehingga fleksibel untuk diakses, teknologi Bootstrap untuk tampilan responsive dan user friendly serta kebutuhan untuk menjalankan sistem pada lingkungan pengguna.

\section{Analisis Kelayakan Operasional}

Kelayakan operasional pada sistem yang diusulkan yaitu mampu menunjang tugas Pimpinan Cabang, mampu menghasilkan output informasi yang dibutuhkan cabang, serta memiliki peranti penunjang sistem.

\section{Analisis Kelayakan Hukum}

Jika ditinjau dari kelayakan hukum, sistem yang diusulkan dibangun menggunakan perangkat lunak yang berlisensi open source. Data peta yang ditampilkan menggunakan library LeafletJS dimana perpustakaan java script tersebut berlisensi open source dan template dashboard sistem menggunakan "Free Bootstrap Admin Template AdminLTE 3" 


\section{Perancangan Sistem}

1) Flowchart

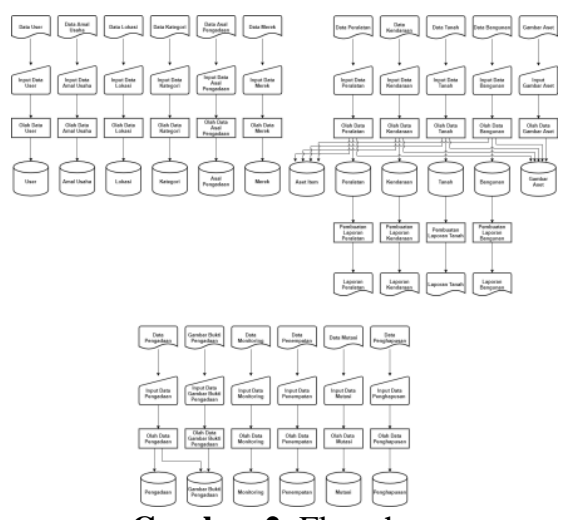

Gambar 2. Flowchart

2) Data Flow Diagram

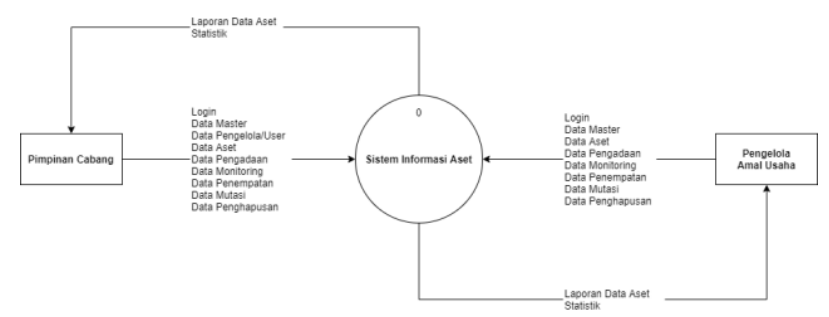

Gambar 3. Data Flow Diagram

3) Entity Relationship Diagram

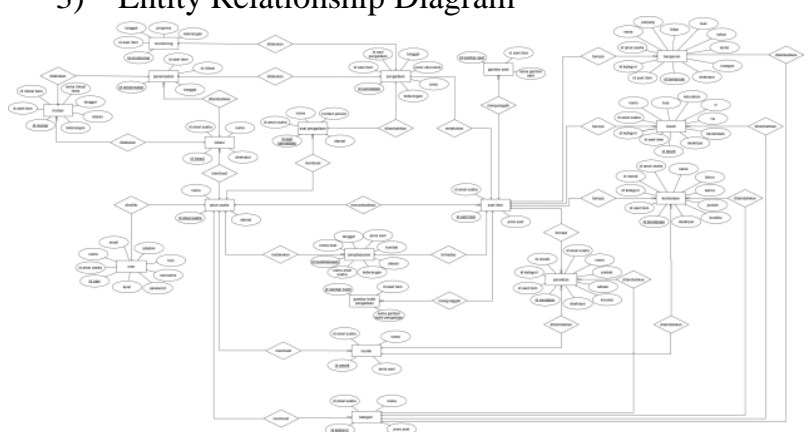

Gambar 4. Entity Relationship Diagram

\section{Perancangan Interface}

Rancangan desain antarmuka pengguna pada sistem yang diusulkan diantaranya adalah:

1) Interface Login

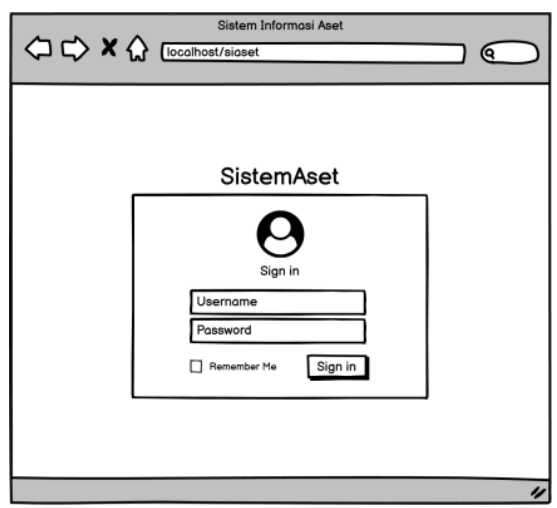

Gambar 5. Interface Login
2) Interface Peralatan

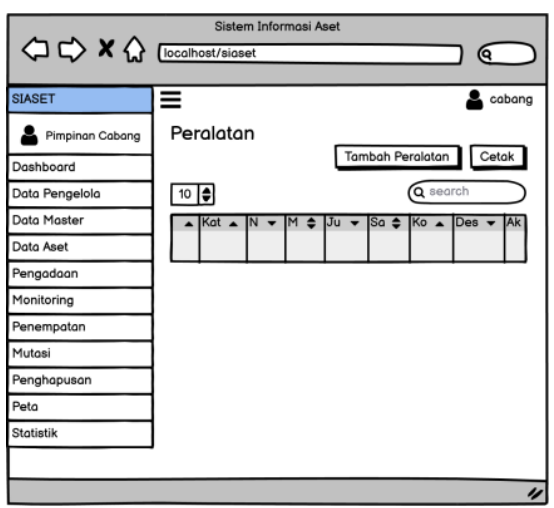

Gambar 6. Interface Peralatan

3) Interface Gambar Aset

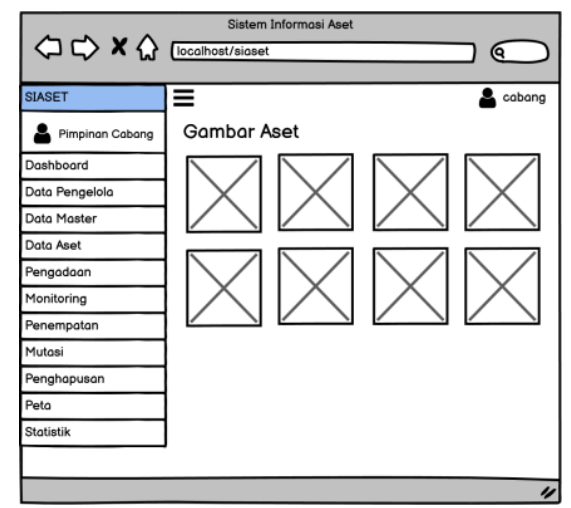

Gambar 7. Interface Gambar Aset

\section{Implementasi}

\section{Database dan Tabel}

Implementasi database pada aplikasi yang dibangun ditunjukkan pada gambar berikut:

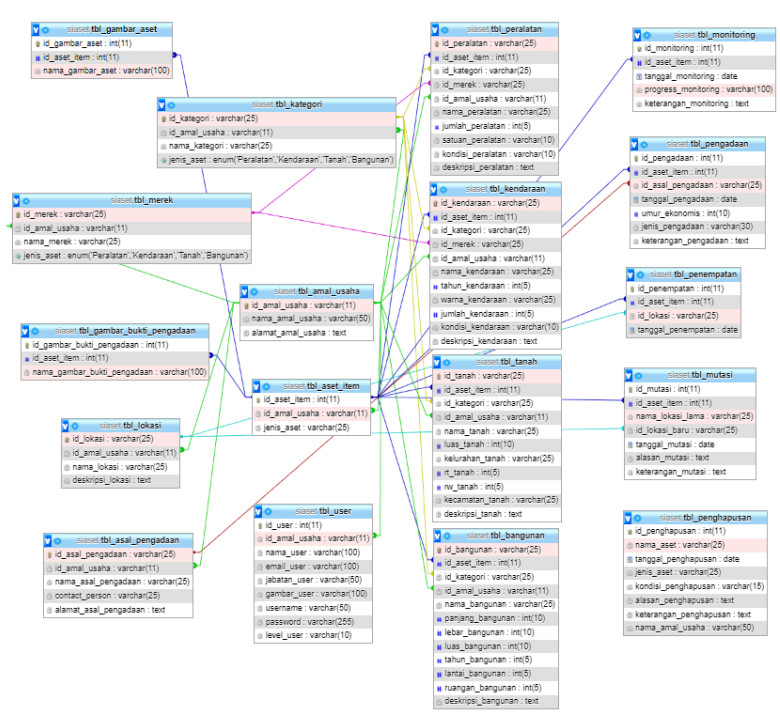

Gambar 8. Relasi Antar Tabel 


\section{Interface}

Implementasi interface pada aplikasi yang telah dibuat adalah sebagai berikut:

1) Interface Login

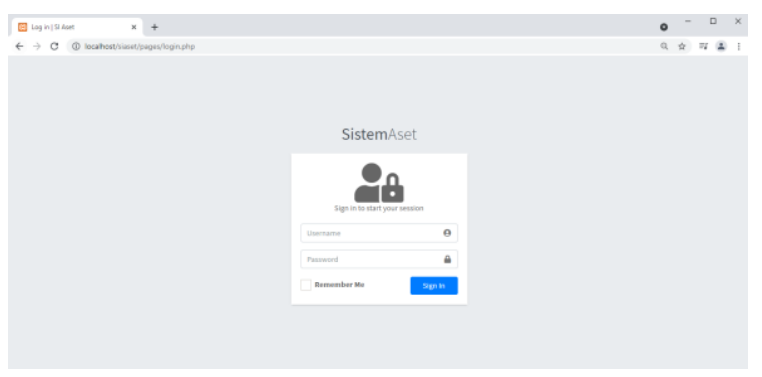

Gambar 9. Interface Login

2) Interface Peralatan

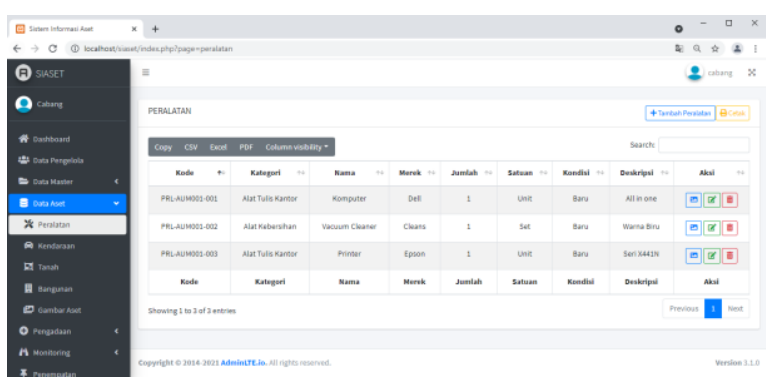

Gambar10. Interface Peralatan

3) Interface Gambar Aset

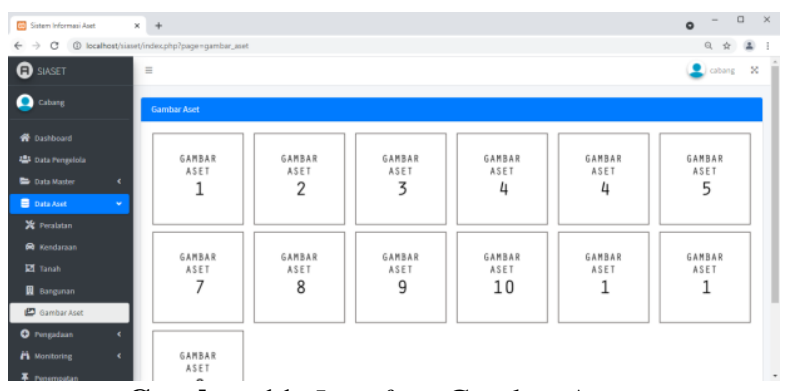

Gambar 11. Interface Gambar Aset

\section{Pengujian Sistem}

Black Box Testing

Tabel 1. Pengujian Black Box

\begin{tabular}{|c|l|l|c|}
\hline $\begin{array}{c}\text { Menu } \\
\text { diujgi }\end{array}$ & \multicolumn{1}{|c|}{$\begin{array}{c}\text { Skenario } \\
\text { Pengujian }\end{array}$} & $\begin{array}{c}\text { Hasil yang } \\
\text { diharapkan }\end{array}$ & Ket. \\
\hline Login & $\begin{array}{l}\text { Memasukkan } \\
\text { username } \text { dan } \\
\text { password } \text { benar }\end{array}$ & $\begin{array}{l}\text { Pengguna masuk } \\
\text { ke dalam sistem }\end{array}$ & Valid \\
\cline { 2 - 4 } & $\begin{array}{l}\text { Memasukkan } \\
\text { username } \\
\text { dan/atau } \\
\text { password } \text { salah }\end{array}$ & $\begin{array}{l}\text { Pengguna gagal } \\
\text { masuk ke dalam } \\
\text { sistem dan } \\
\text { mendapat } \\
\text { notifikasi gagal }\end{array}$ & Valid \\
\cline { 2 - 4 }
\end{tabular}

\begin{tabular}{|c|c|c|}
\hline $\begin{array}{l}\text { Pengguna masuk } \\
\text { lagi ke dalam } \\
\text { sistem } \\
\text { menggunakan } \\
\text { cookie sebelum } 5 \\
\text { menit }\end{array}$ & $\begin{array}{l}\text { Sistem mengecek } \\
\text { cookie dan } \\
\text { username apabila } \\
\text { cocok dapat } \\
\text { langsung masuk } \\
\text { ke dalam sistem }\end{array}$ & Valid \\
\hline $\begin{array}{l}\text { Pengguna } \\
\text { mencoba masuk } \\
\text { ke halaman lain } \\
\text { melalui } \\
\text { pengetikan nama } \\
\text { halaman di url } \\
\text { ketika belum } \\
\text { login }\end{array}$ & $\begin{array}{l}\text { Sistem akan } \\
\text { mengarahkan } \\
\text { pengguna ke } \\
\text { halaman login } \\
\text { selama belum ada } \\
\text { session login }\end{array}$ & Valid \\
\hline
\end{tabular}

\section{Kesimpulan dan Saran}

\section{Kesimpulan}

Berdasarkan pada kegiatan analisis dan perancangan sistem informasi aset pada Muhammadiyah Cabang Minggir yang telah penulis lakukan, dapat disimpulkan bahwa:

1) Prototype sistem informasi aset berbasis website telah berhasil dibuat dengan melakukan analisis menggunakan metode PIECES, kemudian melakukan perancangan sistem menggunakan metode perancangan model data ERD (Entity Relationship Diagram) dan perancangan model proses DFD (Data Flow Diagram). Setelah itu implementasi sistem dengan beberapa macam bahasa pemrograman diantaranya html, css, php, dan javascript. Pengujian sistem dilakukan dengan menggunakan metode white box testing dan black box testing

2) Berdasarkan pengujian yang telah dilakukan sistem mampu melakukan olah data guna menghasilkan output berupa data aset yang dibutuhkan cabang

3) Akses untuk mengetahui data amal usaha secara real time dapat terpenuhi dengan adanya sistem informasi yang menghubungkan antara pimpinan cabang dan pengelola amal usaha

\section{Saran}

Pada kegiatan penelitian yang telah penulis lakukan masih terdapat banyak kekurangan. Penulis memiliki beberapa saran guna dijadikan sebagai bahan perbaikan dalam penelitian selanjutnya, diantaranya adalah:

1) Pembuatan interface aplikasi dibuat lebih efisien agar tidak perlu menggunakan banyak halaman dengan proses yang sama

2) Penambahan fitur multiple insert data dan detail aset dibuat lebih lengkap (termasuk data 
penempatan, mutasi, dll) akan memudahkan pengguna dalam menelusuri aset

3) Bukti pengadaan dibuat tidak hanya format gambar agar lebih fleksibel

\section{Daftar Pustaka}

[1] N. Oktaviani, I. M. Widiarta \& Nurlaily, "Sistem Informasi Inventaris Barang Berbasis Web Pada SMP Negeri 1 Buer," Jurnal JINTEKS, vol. 1, no. 2, pp.160-168, 2019

[2] V. Sihombing, G. J. Yanris, "Penerapan Aplikasi Dalam Mengolah Aset Desa (Studi Kasus : Kepenghuluan Sri Kayangan)," Jurnal Mantik Penusa, vol. 4, no. 1, pp.12-15, 2020

[3] S. Pinem, V. M. Pakpahan, "Aplikasi Inventarisasi Aset Berbasis Web Dengan Metode Waterfall," Jurnal Informatika Universitas Pamulang, vol. 5, no. 2, pp. 208-212, 2020

[4] H. A. Fatta, Analisis \& Perancangan Sistem Informasi untuk Keunggulan Bersaing Perusahaan \& Organisasi Modern, Yogyakarta: Penerbit ANDI, 2007

[5] E. Y. Anggraeni, R. Irviani, Pengantar Sistem Informasi. Yogyakarta: Penerbit ANDI, 2017

[6] M. R. Arief, Pemrograman Web Dinamis menggunakan PHP dan MySQL. Yogyakarta: Penerbit ANDI, 2011.

[7] I. R. Munthe, "Perancangan Sistem Informasi Pengarsipan Data Penduduk Pada Kantor Camat Bilah Hulu Kabupaten Labuhan Batu Dengan Metode System Develovment Life Cycle (SDLC)," Informatika : Jurnal Ilmiah AMIK Labuhan Batu, vol. 5, no. 1, pp. 22-31, 2017

[8] E. Y. Anggraeni, R. Irviani, Pengantar Sistem Informasi. Yogyakarta: Penerbit ANDI, 2017

[9] T. Sutabri, Konsep Sistem Informasi. Yogyakarta: Penerbit ANDI, 2012

[10] M. Mukmin \& Rusnina. "Rancang Bangun Sistem Informasi Pendataan Aset Budaya Pada Benteng Keraton Kesultanan Buton Berbasis Web, " Jurnal Informatika, vol. 7, no. 2, pp. 2129, 2018 